\title{
Feasibility of Neoadjuvant FOLFOX Therapy Without Radiotherapy for Baseline Resectable Rectal Cancer
}

\author{
MICHIHIRO KOIZUMI, TAKESHI YAMADA, SEIICHI SHINJI, YASUYUKI YOKOYAMA, GORO TAKAHASHI, \\ TAKUMA IWAI, KOHKI TAKEDA, KEISUKE HARA, KEIICHIRO OHTA, EIJI UCHIDA and HIROSHI YOSHIDA \\ Department of Gastrointestinal and Hepato-Biliary-Pancreatic Surgery, Nippon Medical School, Tokyo, Japan
}

\begin{abstract}
Background/Aim: The combination of oxaliplatin, leucovorin and fluorouracil (FOLFOX) has been established as postoperative adjuvant chemotherapy for stage III colon cancer. However, the safety and efficacy of neoadjuvant FOLFOX in patients with rectal cancer are still controversial. This prospective pilot study aimed to evaluate the feasibility of neoadjuvant FOLFOX therapy without radiation for baseline resectable rectal cancer $(R C)$. Patients and Methods: The study included 30 patients with clinical stage II/III RC between February 2012 and December 2015. The patients were treated with six cycles of FOLFOX followed by elective surgery. The primary endpoint was the $R 0$ resection rate. The secondary endpoints were the scheduled treatment completion rate, adverse events, pathological response and the diseasefree survival (DFS) rate. Results: All the patients underwent elective $R 0$ resection after neoadjuvant FOLFOX therapy. The completion rate of the 6-cycle regimen was $93.3 \%$ (28/30 patients). Grade 3-4 adverse events occurred in seven patients $(23.3 \%)$. Pathological complete response was noted in two patients (6.7\%). The 3-year DFS rate was $77.5 \%(95 \%$ confidence interval, 61.4\%-93.7\%). Conclusion: Neoadjuvant FOLFOX therapy without radiation is a feasible therapeutic strategy for baseline resectable $R C$.
\end{abstract}

Surgery is the standard treatment for rectal cancer (RC). Total mesorectal excision (TME) is a widely accepted surgical procedure for $\mathrm{RC}$, and it can reduce the local recurrence rate dramatically (1). Research over the past two decades has shown perioperative radiotherapy with or

This article is freely accessible online.

Correspondence to: Takeshi Yamada, Department of Gastrointestinal and Hepato-Biliary-Pancreatic Surgery, Nippon Medical School, 11-5 Sendagi, Bunkyo-ku, Tokyo 113-8603, Japan. Tel: +81 338222131, Fax: +81 356850989, e-mail: y-tak@nms.ac.jp

Key Words: Rectal cancer, neoadjuvant chemotherapy, FOLFOX, feasibility. without chemotherapy followed by TME can reduce the incidence of local recurrence in patients with locally advanced RC further. However, perioperative radiotherapy was not found to improve overall survival (OS) (2-5). To improve oncological outcomes, distant metastasis should be prevented, since distant metastasis is the most important prognostic factor for colorectal cancer.

Postoperative adjuvant chemotherapy can improve the prognosis of patients with stage II/III colon cancer undergoing curative surgery. This improvement is associated with the inhibitive action of these adjuvant chemotherapeutic agents on distant micrometastases that are present at the time of elective surgery. Some cytotoxic agents are used in adjuvant chemotherapy regimens. Among them, oxaliplatinbased regimens are considered the most effective for improving the rates of disease-free survival (DFS) and OS (6-8). Therefore, neoadjuvant chemotherapy (NAC) using oxaliplatin-based regimens for RC is a promising therapeutic strategy for preventing local recurrence through shrinkage of the primary tumour, but also systemic relapse through the action of diminishing latent micrometastases.

However, the efficacy and safety of NAC for the treatment of RC have not been adequately established. Therefore, this single-institution, pilot study aimed to determine the efficacy and safety of NAC involving FOLFOX therapy (5-fluorouracil + L-leucovorin + oxaliplatin).

\section{Patients and Methods}

Patient selection. The protocol of this single-arm, single-institution, phase II study was approved by the institutional review board of Nippon Medical School (Tokyo, Japan) and was conducted in accordance with the tenets of the Declaration of Helsinki. Informed consent was obtained from all the participants prior to their inclusion in this study.

Baseline clinical staging was assessed by colonoscopy, chest and abdominopelvic computed tomography (CT) and pelvic magnetic resonance imaging. Tumours were staged according to the American Joint Committee on Cancer International Union Against Cancer (seventh edition). The presence of a lymph node with a short axis $\geq 5 \mathrm{~mm}$ was considered as confirmation of metastasis (9). 
The inclusion criteria were as follows: (i) histologically proven rectal adenocarcinoma, (ii) location of the centre of the primary tumour under the lower edge of the second sacrum, (iii) RC confirmed as cT3-4, anyN,M0, (iv) no distant metastasis on chest, abdominal and pelvic CT, (v) good physical fitness for elective surgery, (vi) Eastern Cooperative Oncology Group (ECOG) performance status of $0-1$, (vii) age 20-80 years and (viii) adequate hematologic, hepatic and renal functions (i.e. neutrophil count $>1500 / \mathrm{ml}$; platelet count $>100,000 / \mu 1$; estimated glomerular filtration rate $>40 \mathrm{ml} / \mathrm{min} / 1.73 \mathrm{~m}^{2}$; total bilirubin concentration less than twice the upper limit of normal and liver transaminase or alkaline phosphatase levels less than thrice the upper limit of normal).

The exclusion criteria were as follows: (i) intestinal obstruction despite ileostomy or colostomy construction; (ii) T4 tumour invasion of an adjacent organ or the pelvic wall, which was deemed unresectable before administration of any preoperative therapy on the basis of imaging examination; (iii) history of prior chemotherapy and/or radiotherapy of the pelvis; (iv) presence of any other active malignant disease or severe co-morbidity and (v) pregnancy.

Neoadjuvant chemotherapy. Six courses of FOLFOX (day 1, intravenous bolus of oxaliplatin at $85 \mathrm{mg} / \mathrm{m}^{2}$, L-leucovorin at $400 \mathrm{mg} / \mathrm{m}^{2}$ and fluorouracil at $400 \mathrm{mg} / \mathrm{m}^{2}$, followed by continuous infusion at $2,400 \mathrm{mg} / \mathrm{m}^{2}$ for $46 \mathrm{~h}$ ) were administered before surgery. Adverse events of chemotherapy were evaluated according to the National Cancer Institute Common Terminology for Adverse Events, version 4.0.

Surgical procedure. Surgery was performed 2-6 weeks after completion of neoadjuvant FOLFOX therapy. Total or tumourspecific mesorectal excision was performed, with preservation of the bilateral autonomic nerves. Lateral pelvic lymphadenectomy was performed when the tumour was located below the peritoneal reflection and the lateral lymph node was judged as metastatic before neoadjuvant FOLFOX therapy, regardless of the response to therapy.

Pathological evaluation. The extent of the tumour response to neoadjuvant FOLFOX therapy was categorised according to the number of viable carcinoma cells within the tumour as described by the Japanese Classification of Colorectal Carcinoma Version 2 (10) as follows: grade 0, no regression; grade 1a, minimal effect (necrosis of less than one-third of the lesion); grade 1b, mild effect (necrosis of less than two-thirds but one-third or more of the lesion); grade 2, moderate effect (necrosis of more than two-thirds of the lesion) and grade 3, no tumour cells (pathological complete response [pCR]). Patients with a tumour response of grades 2 to $1 \mathrm{~b}$ were considered to have a partial response.

Statistical analysis. The primary endpoint of this study was the R0 resection rate. The secondary endpoints were the scheduled treatment completion rate, adverse events, pathological response, downstaging rate and 3-year DFS rate. The Kaplan-Meier method was used to calculate the event rates. SPSS v21 software (IBM Corp., Armonk, NY, USA) was used to perform all statistical analyses.

\section{Results}

Patient characteristics. This study enrolled 30 patients between February 2012 and December 2015. Table I shows the patient characteristics. The majority of patients $(90 \%)$
Table I. Baseline characteristics of patients.

\begin{tabular}{|c|c|}
\hline \multicolumn{2}{|l|}{ Age, years } \\
\hline Median & 63 \\
\hline Range & $39-77$ \\
\hline \multicolumn{2}{|l|}{ Gender, n (\%) } \\
\hline Male & $24(80.0)$ \\
\hline Female & $6(20.0)$ \\
\hline \multicolumn{2}{|l|}{ ECOG performance status, $\mathrm{n}(\%)$} \\
\hline 0 & $28(93.3)$ \\
\hline 1 & $2(6.7)$ \\
\hline \multicolumn{2}{|l|}{ Body mass index, $\mathrm{kg} / \mathrm{m}^{2}$} \\
\hline Median & 22.1 \\
\hline Range & $17.0-32.2$ \\
\hline \multicolumn{2}{|l|}{ Tumour size, $\mathrm{mm}$} \\
\hline Median & 40.1 \\
\hline Range & $20.0-56.7$ \\
\hline \multicolumn{2}{|l|}{ Distance from the $\mathrm{AV}, \mathrm{mm}$} \\
\hline Median & 50 \\
\hline Range & $0-100$ \\
\hline \multicolumn{2}{|l|}{ Carcinoembryonic antigen level, $\mathrm{ng} / \mathrm{mL}$} \\
\hline Median & 4.3 \\
\hline Range & $1.6-46.0$ \\
\hline \multicolumn{2}{|l|}{ Histological type, n (\%) } \\
\hline Well-differentiated adenocarcinoma & $15(50.0)$ \\
\hline Moderately differentiated adenocarcinoma & $15(50.0)$ \\
\hline \multicolumn{2}{|l|}{ Clinical T-stage, $\mathrm{n}(\%)$} \\
\hline $\mathrm{T} 3$ & $27(90.0)$ \\
\hline $\mathrm{T} 4 \mathrm{~b}$ & $3(10.0)$ \\
\hline \multicolumn{2}{|l|}{ Clinical N-stage, n (\%) } \\
\hline No & $2(20.0)$ \\
\hline $\mathrm{N} 1$ & $12(40.0)$ \\
\hline $\mathrm{N} 2$ & $12(40.0)$ \\
\hline
\end{tabular}

AV: Anal verge; ECOG: Eastern Cooperative Oncology Group.

had cT3 tumours. Three patients had cT4b tumours, and of these patients, two showed invasion of the levator ani muscle and one showed invasion of the seminal vesicles. All cT4b tumours were considered resectable at baseline assessment.

Treatment exposure and adverse events. The completion rate of the scheduled 6-cycle treatment regimen was $93.3 \%$ (28/30). Two patients received five cycles. One patient with an adverse event of peripheral neuropathy and another with nausea refused the last cycle. The relative dose intensities of oxaliplatin, bolus 5-FU and infused 5-FU were $95.8 \%$, $98.9 \%$ and $98.9 \%$, respectively.

Table II shows the adverse events. The overall rate of any grade of adverse events during the scheduled treatment regimen was $80.0 \%(24 / 30)$. The most common adverse event was peripheral neuropathy $(53.3 \%, 16 / 30)$. Grade 3 4 adverse events developed in $23.3 \%$ (7/30) of patients, and all patients had neutropenia. No patients had febrile neutropenia. 
Table II. Adverse events of neoadjuvant FOLFOX.

\begin{tabular}{lcc}
\hline & \multicolumn{2}{c}{$\mathrm{n}(\%)$} \\
\cline { 2 - 3 } & Any grade & Grade 3-4 \\
\hline Leukopenia & $11(36.7)$ & $7(23.3)$ \\
Thrombopenia & $1(3.3)$ & 0 \\
Anaemia & $2(6.6)$ & 0 \\
ALT & $4(13.3)$ & 0 \\
AST & $4(13.3)$ & 0 \\
Total bilirubin & $1(3.3)$ & 0 \\
Peripheral neuropathy & $16(53.3)$ & 0 \\
Nausea & $9(33.3)$ & 0 \\
Hand-foot syndrome & $3(10.0)$ & 0 \\
Pneumonia & $1(3.3)$ & 0 \\
Stomatitis & $1(3.3)$ & 0 \\
\hline
\end{tabular}

ALT: Alanine aminotransferase; AST: aspartate aminotransferase.

Table III. Surgical outcomes.

\begin{tabular}{lc}
\hline & $\mathrm{n}(\%)$ \\
\hline R0 resection & $30(100)$ \\
Procedure & $18(60.0)$ \\
Low anterior resection & $4(13.3)$ \\
Intersphincteric resection & $8(26.7)$ \\
Abdominoperineal resection & \\
Approach & $27(90.0)$ \\
Laparoscopic & $3(10.0)$ \\
Open & $6(20.0)$ \\
Postoperative complications* & $3(13.6)$ \\
Anastomotic leakage** & $2(6.6)$ \\
Bowel obstruction & $2(6.6)$ \\
Wound infection & $1(3.3)$ \\
Stomal necrosis & $1(3.3)$ \\
Intra-abdominal abscess & \\
ypStage & $3(10.0)$ \\
0 & $5(16.7)$ \\
I & $12(40.0)$ \\
II & $10(33.3)$ \\
III & \\
Tumour response & $2(6.7)$ \\
3 & $8(26.7)$ \\
2 & $7(23.3)$ \\
1b & $11(36.7)$ \\
1a & $2(6.7)$ \\
0 &
\end{tabular}

*Greater than grade II according to the Clavien-Dindo classification. **Sphincter-sparing surgery.

Surgery. All the 30 patients scheduled for elective surgery underwent R0 resection. The median duration from the last cycle of neoadjuvant FOLFOX therapy to tumour resection was 32 days (range $=16-46$ days). One patient requested to undergo surgery beyond the planned interval at day 46. Table
Table IV. Downstaging of $T$ and $N$-factor after neoadjuvant FOLFOX.

\begin{tabular}{|c|c|c|c|c|c|c|c|}
\hline \multicolumn{8}{|c|}{ T-factor downstaging } \\
\hline & урT0 & ypTis & ypT1 & урT2 & ypT3 & ypT4a & ypT4b \\
\hline cT3 & 2 & 1 & & 5 & 19 & & \\
\hline cT4b & & & & 1 & 1 & & 1 \\
\hline \multicolumn{8}{|c|}{$\mathrm{N}$-factor downstaging } \\
\hline & ypN0 & ypN1a & ypN1b & ypN2a & ypN2b & & \\
\hline $\mathrm{cN} 0$ & 6 & & & & & & \\
\hline $\mathrm{cN} 1$ & 7 & 3 & 1 & 1 & & & \\
\hline $\mathrm{cN} 2$ & 9 & 1 & & 1 & 1 & & \\
\hline
\end{tabular}

Table V. Relationship between ypT and ypN stage.

\begin{tabular}{lccccccc}
\hline & урT0 & урTis & урT1 & урT2 & урT3 & урT4a & урT4b \\
\hline ypN0 & 2 & 1 & & 6 & 11 & 1 \\
ypN1 & & & & & 6 & \\
ypN2 & & & & & 3 & \\
\hline
\end{tabular}

III shows the surgical outcomes. Three patients with cT4 tumours underwent radical resection combined with total mesorectal excision involving adjacent organs (the levator ani in two patients and the seminal vesicle in one patient). Sphincter-sparing resection was performed in $73.3 \%(22 / 30)$ of the patients. Postoperative complications (grade $\geq 2$ ) were noted in $20 \%(6 / 30)$ of the patients. Reoperation was needed in patients with stomal necrosis. Three patients with anastomotic leakage were treated with tubal drainage, and no further surgery was performed.

Pathological outcomes. Table III shows the pathological results. pCR was observed in two patients $(6.7 \%)$, and partial response was observed in 15 patients $(50.0 \%)$. Although 13 patients $(43.3 \%)$ had a poor response, including two patients $(6.7 \%)$ with no response, planned surgery was performed and all patients underwent $\mathrm{R} 0$ resection.

Among the 30 patients, $18(60 \%)$ showed clinical downstaging (cStage II to ypStage 0 -I and cStage III to ypStage 0-III) after NAC when compared with the clinical stage before NAC. Table IV shows $\mathrm{T}$ and $\mathrm{N}$-factor downstaging. T-factor downstaging was observed in 10 (33.3\%) patients. Among 27 patients with cT3 tumours, ypT0 was noted in two patients, ypTis in 1, ypT2 in 5 and ypT3 in 19. Among 3 patients with cT4b tumours, ypT2, ypT3 and 
ypT4b (seminal vesicle) were each noted in one patient. $\mathrm{N}$-factor downstaging (cN1 to ypN0 and $\mathrm{cN} 2$ to ypN0-1) was observed in $17(70.8 \%)$ of 24 patients. All six patients with cN0 were judged as ypN0. Of the 24 patients, 16 did not have lymph node metastasis histopathologically. Table V shows the relationship between ypT and ypN. Nine patients showed T-factor downstaging to less than T2, and they did not have lymph node metastasis, although 6 patients were judged as $\mathrm{cN}+$. On the other hand, among 20 patients with ypT3, 9 (40.0\%) had lymph node metastasis.

Survival. The median follow-up period was 31.1 months (range $=9-54$ months). The 3-year OS and DFS rates in all patients were $95.7 \%$ (95\% confidence interval $[\mathrm{CI}]=87.3 \%$ $100 \%)$ and $77.5 \%(95 \% \mathrm{CI}=61.4 \%-93.7 \%)$, respectively (Figure 1). Two patients had anastomotic recurrence, and both patients underwent a second surgery to excise the recurrence. They have had no relapse after the second surgery. Five patients developed distant metastases (lung 2 and liver 3), and two patients died from metastatic disease (lung 1 and liver 1).

\section{Discussion}

In this study, NAC involving six cycles of neoadjuvant FOLFOX followed by elective surgery was associated with a $\mathrm{R} 0$ resection rate of $100 \%$ and a pCR rate of $6.7 \%$. Additionally, the scheduled treatment completion rate was $93.3 \%$, and grade 3-4 adverse events were observed in $23.3 \%$ of patients.

The advantage of NAC is that effective chemotherapeutic agents are administered at an early stage of treatment when the tumour is still intact. Tumour shrinkage can improve the local control of surgery, and exposure of undetected distant micrometastases may reduce the risk of recurrence after surgery. NAC could be considered a promising therapeutic strategy for improving the oncological outcomes of RC. Also, the R0 resection rate was used as the primary endpoint. R0 resection rate after NAC was $100 \%$ among patients who were judged to be capable of undergoing radical excision at baseline. Previous reports also showed the $\mathrm{R} 0$ resection rates of NAC for cT3-4 (except T4b) were high, ranging from $98.3 \%$ to $100 \%$ (11-14). An important problem inherent in preoperative treatment is that surgical curability may be impaired by tumour growth during the treatment. In this study, although 13 patients showed no response histologically, the tumours did not develop clinically during NAC and the therapy did not hinder surgical curability. This is an important finding to support future research on whether NAC will improve prognosis.

Our strategy had a therapy completion rate of $93.3 \%$ with high relative dose intensity. A neoadjuvant setting has the advantage of administering planned systemic chemotherapy,

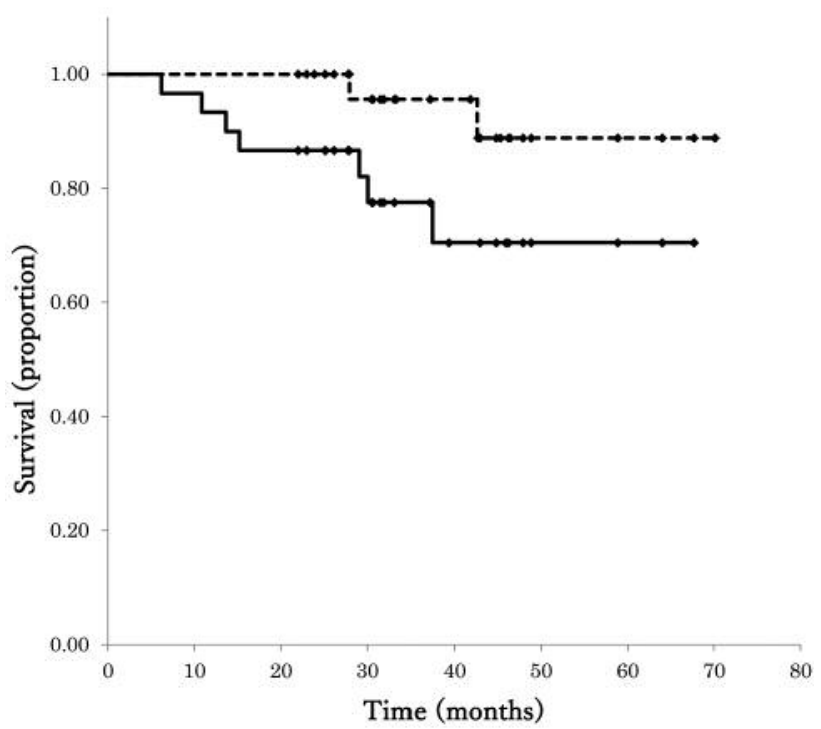

Figure 1. Kaplan-Meier plots of disease-free survival (DFS) and overall survival (OS) for the 30 study patients.

as patients are in a good performance status. In order to increase the effects of adjuvant chemotherapy, it is necessary not only to administer a powerful cytotoxic agent but also to maintain a high dose intensity. Although the grade 3-4 neutropenia rate was $23.3 \%$, which was higher than that reported in previous oxaliplatin-based NAC studies (0\%-4.0\%) (14-18), adverse events were controlled by appropriate drug reduction or withdrawal. Previous studies reported that $32.6 \%$ $42 \%$ of patients had grade 3-4 neutropenia after 6 months of postoperative adjuvant chemotherapy (FOLFOX/CapeOX [capecitabine + L-leucovorin + oxaliplatin]) (19-21). Additionally, the TOSCA trial investigated the optimal therapy period (3vs. 6 months) and reported that the rate of grade 34 neutropenia in the 3 -month arm was $19.3 \%$ (22). Based on these results, our results are considered reasonable.

In locally advanced RC, NACRT combined with TME can result in a low local recurrence rate. However, NACRT did not improve OS in previous studies (2-5). Several factors might be associated with this result. First, the effect of the chemotherapeutic agent 5-FU used as a radiosensitiser might be insufficient to decrease distant metastasis. Second, the induction rate of adjuvant chemotherapy after NACRT might be low, and the rate in EORTC22921 was $43 \%$ (5) and in CHRONICLE was $48 \%$ (23). The final goal of NAC is prognostic improvement. In the neoadjuvant setting it is reasonable to administer chemotherapeutic agents for decreasing distant metastasis and improving OS. To reveal the prognostic outcomes of the NAC approach, the PROSPECT study (US, NCT01515787) comparing 
neoadjuvant FOLFOX followed by selective use of NACRT to standard NACRT is ongoing.

In this study, the response rate was $56.7 \%$ and the $\mathrm{pCR}$ rate was $6.7 \%$. Previous studies on oxaliplatin-based regimens without a molecular-target drug revealed a pCR rate of $6.6 \%$ $12.2 \%(14,17,18,24)$. The pCR rate might increase with the addition of a molecular-target drug. The pCR rate was $13.3 \%$ $25 \%$ for regimens that involved bevacizumab $(11-13,15)$ and was $18 \%$ for regimens that involved cetuximab (13). However, the relationship between histological response and prognosis in NAC has not been clarified, though many reports on NACRT showed pCR and good histological response were associated with a good prognosis (25-28). AlGizawy et al. (14) reported on NAC involving XELOX plus bevacizumab and mentioned that this strategy had a high pCR of $20 \%$ and a 2 -year DFS rate of $70 \%$. On the other hand, our strategy had a low pCR of $6.7 \%$ and a 3-year DFS rate of $77.5 \%$. Thus, any positive response may be the goal of NAC for improving prognosis. To judge the validity of adding a molecular-target drug, it is necessary to clarify the significance of increasing the pCR rate in NAC.

The additive effect of a molecular-target drug on prognostic improvement in postoperative adjuvant chemotherapy of colon cancer has not been shown. Presently, it is questionable to add a molecular-target drug to NAC for resectable RC to improve prognostic outcomes. With regard to T4 and bulky T3 tumours that cannot easily undergo R0 resection, a phase two study on XELOX and a bevacizumab regimen for such locally advanced $\mathrm{RC}$ reported $\mathrm{R} 0$ resection rates of $90-100 \%(16,29)$. The addition of a molecular-target drug to NAC may help in the treatment of borderline and unresectable RC.

For locally advanced RC, the standard approach is TME (LAR or APR) (low anterior resection or abdominoperineal resection). However, a paradigm shift is occurring recently. Selected patients with complete (ycT0N0) and good (ycT1$2 \mathrm{~N} 0$ ) responses to NACRT are considered as candidates for organ preservation strategies, including local excision (LE) $(30,31)$ or strict follow-up without operation (watch-andwait approach) (32-34). Organ preservation is a promising strategy to decrease postoperative complications and impairments in anorectal function and quality of life, which are associated with TME. Although the indication of organ preservation is debatable still, a meta-analysis by Shaikh et al. reported that OS and DFS in cT3anyN patients, who underwent NACRT, showed no difference between LE and TME (35). In our study, nine patients (30.0\%) with downstaging to less than ypT2 had ycN0 despite including six patients with $\mathrm{cN}+$. Shrinkage of the primary tumour by NAC can reflect the disappearance of latent lymph node metastasis, and the absence of lymph node metastasis is essential for LE. Our results suggested that NAC may be an option for organ preservation.
The present study had certain limitations. Only RC cases judged as resectable before treatment were included. Therefore, further studies are needed to evaluate the R0 and local recurrence rates of neoadjuvant FOLFOX in cases of borderline or unresectable RC. In addition, this was a singleinstitution, pilot study and the number of samples was relatively small. Therefore, to clarify the effects of FOLFOX on the prognosis of RC patients after surgery, a larger randomised control trial is needed.

In conclusion, NAC involving FOLFOX is a safe and feasible treatment for baseline resectable RC. NAC is a promising therapeutic strategy that avoids the adverse events of radiation, which are problems in NACRT, and it can improve prognosis.

\section{Conflicts of Interest}

The Authors declare that they have no conflicts of interest.

\section{References}

1 Heald RJ and Ryall RD: Recurrence and survival after total mesorectal excision for rectal cancer. Lancet 1: 1479-1482, 1986.

2 van Gijn W, Marijnen CA, Nagtegaal ID, Kranenbarg EM, Putter H, Wiggers T, Rutten HJ, L. Påhlman L, Glimelius B and van de Velde CJ: Preoperative radiotherapy combined with total mesorectal excision for resectable rectal cancer: 12-year followup of the multicentre, randomised controlled TME trial. Lancet Oncol 12: 575-582, 2011.

3 Sauer R, Becker H, Hohenberger W, Rödel C, Wittekind C, Fietkau R, Martus P, Tschmelitsch J, Hager E, Hess CF, Karstens JH, Liersch T, Schmidberger H and Raab R: Preoperative versus postoperative chemoradiotherapy for rectal cancer. N Engl J Med 351: 1731-1740, 2004.

4 Bujko K, Nowacki MP, Nasierowska-Guttmejer A, Michalski W, Bebenek M and Kryj M: Long-term results of a randomized trial comparing preoperative short-course radiotherapy with preoperative conventionally fractionated chemoradiation for rectal cancer. Br J Surg 93: 1215-1223, 2006.

5 Bosset JF, Collette L, Calais G, Mineur L, Maingon P, Radosevic-Jelic L, Daban A, Bardet E, Beny A and Ollier JC: Chemotherapy with preoperative radiotherapy in rectal cancer. N Engl J Med 355: 1114-1123, 2006.

6 Kuebler JP, Wieand HS, O'Connell MJ, Smith RE, Colangelo LH, Yothers G, Petrelli NJ, Findlay MP, Seay TE, Atkins JN, Zapas JL, Goodwin JW, Fehrenbacher L, Ramanathan RK, Conley BA, Flynn PJ, Soori G, Colman LK, Levine EA, Lanier KS and Wolmark N: Oxaliplatin combined with weekly bolus fluorouracil and leucovorin as surgical adjuvant chemotherapy for stage II and III colon cancer: results from NSABP C-07. J Clin Oncol 25: 2198-2204, 2007.

7 André T, Boni C, Navarro M, Tabernero J, Hickish T, Topham C, Bonetti A, Clingan P, Bridgewater J, Rivera F and de Gramont A: Improved overall survival with oxaliplatin, fluorouracil, and leucovorin as adjuvant treatment in stage II or III colon cancer in the MOSAIC trial. J Clin Oncol 27: 3109$3116,2009$. 
8 Haller DG, Tabernero J, Maroun J, de Braud F, Price T, van Cutsem E, Hill M, Gilberg F, Rittweger K and Schmoll HJ: Capecitabine plus oxaliplatin compared with fluorouracil and folinic acid as adjuvant therapy for stage III colon cancer. J Clin Oncol 29: 1465-1471, 2011.

9 Ogawa S, Hida J, Ike H, Kinugasa T, Ota M, Shinto E, Itabashi M, Kameoka S and Sugihara K: Selection of lymph node-positive cases based on perirectal and lateral pelvic lymph nodes using magnetic resonance imaging: study of the Japanese Society for Cancer of the Colon and Rectum. Ann Surg Oncol 23: 1187-1194, 2016

10 Japanese Society for Cancer of the Colon and Rectum: Japanese classification of colorectal carcinoma. Tokyo, Kanehara \& Co., 2009.

11 Schrag D, Weiser MR, Goodman KA, Gonen M, Hollywood E, Cercek A, Reidy-Lagunes DL, Gollub KJ, Shia J, Guillem JG, Temple LK, Paty PB and Saltz LB: Neoadjuvant chemotherapy without routine use of radiation therapy for patients with locally advanced rectal cancer: a pilot trial. J Clin Oncol 32: 513-518, 2014.

12 Fernandez-Martos C, Brown G, Estevan R, Salud A, Montagut C, Maurel J, Safont MJ, Aparicio J, Feliu J, Vera R, Alonso V, Gallego J, Martin M, Pera M, Sierra E, Serra J, Delgado S, Roig JV, Santos J and Pericay C: Preoperative chemotherapy in patients with intermediate-risk rectal adenocarcinoma selected by high-resolution magnetic resonance imaging: the GEMCAD 0801 Phase II Multicenter Trial. Oncologist 19: 1042-1043, 2014.

13 Hasegawa S, Goto S, Matsumoto T, Hida K, Kawada K, Matsusue R, Yamaguchi T, Nishitai R, Manaka D, Kato S, Kadokawa Y, Yamanokuchi S, Kawamura J, Zaima M, Kyogoku T, Kanazawa A, Mori Y, Kanai M, Matsumoto S and Sakai Y: A multicenter phase 2 study on the feasibility and efficacy of neoadjuvant Chemotherapy without radiotherapy for locally advanced rectal cancer. Ann Surg Oncol 24: 3587-3595, 2017.

14 AlGizawy SM, Essa HH and Ahmed BM: Chemotherapy alone for patients with stage II/III rectal cancer undergoing radical surgery. Oncologist 20: 752-757, 2015.

15 Uehara K, Hiramatsu K, Maeda A, Sakamoto E, Inoue M, Kobayashi S, Tojima Y, Yoshioka Y, Nakayama G, Yatsuya H, Ohmiya N, Goto $\mathrm{H}$ and Nagino M: Neoadjuvant oxaliplatin and capecitabine and bevacizumab without radiotherapy for poor-risk rectal cancer: N-SOG 03 phase II trial. Jpn J Clin Oncol 43: 964971, 2013.

16 Hasegawa J, Nishimura J, Mizushima T, Miyake Y, Kim HM, Takemoto H, Tamagawa H, Noura S, Fujii M, Fujie Y, Kato T, Miwa H, Takemasa I, Ikeda M, Yamamoto H, Sekimoto M, Nezu R, Doki Y and Mori M: Neoadjuvant capecitabine and oxaliplatin (XELOX) combined with bevacizumab for high-risk localized rectal cancer. Cancer Chemother Pharmacol 73: 1079-1087, 2014.

17 Kamiya T, Uehara K, Nakayama G, Ishigure K, Kobayashi S, Hiramatsu K, Nakayama H, Yamashita K, Sakamoto E, Tojima Y, Kawai S, Kodera $\mathrm{Y}$ and Nagino $\mathrm{M}$ : Early results of multicenter phase II trial of perioperative oxaliplatin and capecitabine without radiotherapy for high-risk rectal cancer: CORONA I study. Eur J Surg Oncol 42: 829-835, 2016.

18 Ueki T, Manabe T, Inoue S, Ienaga J, Yamanaka N, Egami T, Ishikawa M, Konomi H, Ikubo A, Nagayoshi K, Nakamura M and Tanaka M: A feasibility study of neoadjuvant XELOX without radiotherapy for locally advanced lower rectal cancer. Anticancer Res 36: 741-747, 2016.
19 Allegra CJ, Yothers G, O'Connell MJ, Sharif S, Colangelo LH, Lopa SH, Petrelli NJ, Goldberg RM, Atkins JN, Seay TE, Fehrenbacher L, O'Reilly S, Chu L, Azar CA and Wolmark N: Initial safety report of NSABP C-08: a randomized phase III study of modified FOLFOX6 with or without bevacizumab for the adjuvant treatment of patients with stage II or III colon cancer. J Clin Oncol 27: 3385-3390, 2009.

20 Andre T, Boni C, Monudeji-Boudiaf L, Navarro M, Tabernero J, Hickish T, Topham C, Zaninelli M, Clingan P, Bridgewater J, Tabah-Fisch I and de Gramont A, Multicenter International Study of Oxaliplatin/5-Fluorouracil/Leucovorin in the Adjuvant Treatment of Colon Cancer (MOSAIC) Investigators: Oxaliplatin, fluorouracil, and leucovorin as adjuvant treatment for colon cancer. N Engl J Med 350: 2343-2351, 2004.

21 de Gramont A, van Cutsem E, Schmoll HJ, Tabernero J, Clarke S, Moore MJ, Cunningham D, Cartwright TH, Hecht JR, Rivera F, Im SA, Bodoky G, Salazar R, Maindrault-Goebel F, ShachamShmueli E, Bajetta E, Makrutzki M, Shang A, André T and Hoff PM: Bevacizumab plus oxaliplatin-based chemotherapy as adjuvant treatment for colon cancer (AVANT): A phase III randomised controlled trial. Lancet Oncol 13: 1225-1233, 2012.

22 Lonardi S, Sobrero A, Rosati G, Di Bartolomeo M, Ronzoni M, Aprile G, Scartozzi M, Banzi M, Zampino MZ, Pasini F, Marchetti P, Cantore M, Zaniboni A, Rimassa L, Ciuffreda L, Ferrari D, Barni S, Zagonel V, Maiello E, Rulli E and Labianca R: Phase III trial comparing 3-6 months of adjuvant FOLFOX4/XELOX in stage II-III colon cancer: Safety and compliance in the TOSCA trial. Ann Oncol 27: 2074-2081, 2016.

23 Glynne-Jones R, Counsell N, Quirke P, Mortensen N, Maraveyas A, MeadowsHM, Ledermann $\mathrm{J}$ and Sebag-Montefiore D: Chronicle: Results of a randomised phase III trial in locally advanced rectal cancer after neoadjuvant chemoradiation randomising postoperative adjuvant capecitabine plus oxaliplatin (XELOX) versus control. Ann Oncol 25: 1356-1362, 2014

24 Deng Y, Chi P, Lan P, Wang L, Chen W, Cui L, Chen D, Cao J, Wei H, Peng X, Huang Z, Cai G, Zhao R, Huang Z, Xu L, Zhou H, Wei Y, Zhang H, Zheng J, Huang Y, Zhou Z, Cai Y, Kang L, Huang M, Peng J, Ren D and Wang J: Modified FOLFOX6 with or without radiation versus fluorouracil and leucovorin with radiation in neoadjuvant treatment of locally advanced rectal cancer: Initial results of the Chinese FOWARC multicenter, open-label, randomized three-arm phase III trial. J Clin Oncol 34: 3300-3307, 2016.

25 Maas M, Nelemans PJ, Valentini V, Das P, Rödel C, Kuo LJ, Calvo FA, García-Aguilar J, Glynne-Jones R, Haustermans K, Mohiuddin M, Pucciarelli S, Small W Jr., Suárez J, Theodoropoulos G, Biondo S, Beets-Tan RG and Beets GL: Long-term outcome in patients with a pathological complete response after chemoradiation for rectal cancer: a pooled analysis of individual patient data. Lancet Oncol 11: 835-844, 2010.

26 de Campos-Lobato LF, Stocchi L, da Luz Moreira A, Geisler D, Dietz DW, Lavery IC, Fazio VW and Kalady MF: Pathologic complete response after neoadjuvant treatment for rectal cancer decreases distant recurrence and could eradicate local recurrence. Ann Surg Oncol 18: 1590-1598, 2011.

27 Rödel C, Martus P, Papadoupolos T, Füzesi L, Klimpfinger M, Fietkau R, Liersch T, Hohenberger W, Raab R, Sauer R and Wittekind C: Prognostic significance of tumor regression after preoperative chemoradiotherapy for rectal cancer. J Clin Oncol 23: 8688-8696, 2005. 
28 Capirci C, Valentini V, Cionini L, De Paoli A, Rodel C, GlynneJones R, Coco C, Romano M, Mantello G, Palazzi S, Mattia FO, Friso KL, Genovesi D, Vidali C, Gambacorta MA, Buffoli A, Lupattelli M, Favretto MS and La Torre G: Prognostic value of pathologic complete response after neoadjuvant therapy in locally advanced rectal cancer: Long-term analysis of 566 ypCR patients. Int J Radiat Oncol Biol Phys 72: 99-107, 2008.

29 Uehara K, Ishiguro S, Sakamoto E, Maeda A, Inoue M, Tojima Y, Kobayashi S, Omiya N, Ishizuka N, Nakao A, Goto H and Nagino M: Phase II trial of neoadjuvant chemotherapy with XELOX plus bevacizumab for locally advanced rectal cancer. Jpn J Clin Oncol 41: 1041-1044, 2011.

30 Garcia-Aguilar J, Renfro LA, Chow OS, Shi Q, Carrero XW, Lynn PB, Thomas CR, Chan E, Cataldo PA, Marcet JE, Medich DS, Johnson CS, Oommen SC, Wolff BG, Pigazzi A, McNevin SM, Pons RK and Bleday R: Organ preservation for clinical T2N0 distal rectal cancer using neoadjuvant chemoradiotherapy and local excision (ACOSOG Z6041): Results of an open-label, single-arm, multi-institutional, phase 2 trial. Lancet Oncol 16: 1537-1546, 2015.

31 Rullier E, Rouanet P, Tuech JJ, Valverde A, Lelong B, Rivoire M, Faucheron JL, Jafari M, Portier G, Meunier B, Sileznieff I, Prudhomme M, Marchal F, Pocard M, Pezet D, Rullier A, Vendrely V, Denost Q, Asselineau J and Doussau A: Organ preservation for rectal cancer (GRECCAR 2): a prospective, randomised, open-label, multicentre, phase 3 trial. Lancet 390 : 469-479, 2017.
32 Habr-Gama A, Perez RO, Nadalin W, Sabbaga J, Ribeiro U Jr., Silva e Sousa AH Jr., Campos FG, Kiss DR and GamaRodrigues J: Operative versus nonoperative treatment for stage 0 distal rectal cancer following chemoradiation therapy: longterm results. Ann Surg 240: 711-718, 2004.

33 Appelt AL, Pløen J, Harling H, Jensen FS, Jensen LH, Jørgensen JC, Lindebjerg J, Rafaelsen SR and Jakobsen A: High-dose chemoradiotherapy and watchful waiting for distal rectal cancer: a prospective observational study. Lancet Oncol 16: 2015-2016, 2015.

34 Renehan AG, Malcomson L, Emsley R, Gollins S, Maw A, Myint AS, Rooney PS, Susnerwala S, Blower A, Saunders MP, Wilson MS, Scott N and O'Dwyer: Watch-and-wait approach versus surgical resection after chemoradiotherapy for patients with rectal cancer (the OnCoRe project): a propensity-score matched cohort analysis. Lancet Oncol 17: 174-183, 2016.

35 Shaikh I, Askari A, Ourû S, Warusavitarne J, Athanasiou T and Faiz O: Oncological outcomes of local excision compared with radical surgery after neoadjuvant chemoradiotherapy for rectal cancer: a systematic review and meta-analysis. Int J Colorectal Dis 30: 19-29, 2014.

Received April 6, 2018

Revised May 8, 2018

Accepted May 9, 2018 